Check for updates

Cite this: Chem. Sci., 2020, 11, 396

๑ All publication charges for this article have been paid for by the Royal Society of Chemistry

Received 21st August 2019

Accepted 11th November 2019

DOI: $10.1039 / c 9 s c 04197 d$

rsc.li/chemical-science

\title{
Unique aqueous self-assembly behavior of a thermoresponsive diblock copolymer $\dagger$
}

\author{
Sarah J. Byard, ${ }^{a}$ Cate T. O'Brien, ${ }^{a}$ Matthew J. Derry, (D) a Mark Williams, ${ }^{a}$ \\ Oleksandr O. Mykhaylyk, (D) adam Blanazs (D) ${ }^{b}$ and Steven P. Armes (D)*a
}

\begin{abstract}
It is well-recognized that block copolymer self-assembly in solution typically produces spheres, worms or vesicles, with the relative volume fraction of each block dictating the copolymer morphology. Stimulusresponsive diblock copolymers that can undergo either sphere/worm or vesicle/worm transitions are also well-documented. Herein we report a new amphiphilic diblock copolymer that can form spheres, worms, vesicles or lamellae in aqueous solution. Such self-assembly behavior is unprecedented for a single diblock copolymer of fixed composition yet is achieved simply by raising the solution temperature from $1{ }^{\circ} \mathrm{C}$ (spheres) to $25{ }^{\circ} \mathrm{C}$ (worms) to $50{ }^{\circ} \mathrm{C}$ (vesicles) to $70{ }^{\circ} \mathrm{C}$ (lamellae). Heating increases the degree of hydration (and hence the effective volume fraction) of the core-forming block, with this parameter being solely responsible for driving the sphere-to-worm, worm-to-vesicle and vesicle-to-lamellae transitions. The first two transitions exhibit excellent reversibility but the vesicle-tolamellae transition exhibits hysteresis on cooling. This new thermoresponsive diblock copolymer provides a useful model for studying such morphological transitions and is likely to be of significant interest for theoretical studies.
\end{abstract}

\section{Introduction}

Block copolymer self-assembly has been extensively studied because it offers a wide range of potential applications, including thermoplastic elastomers, ${ }^{1}$ catalysts, ${ }^{2}$ toughening agents for epoxy resins, ${ }^{3}$ ultrafiltration membranes, ${ }^{4}$ lithographic materials, ${ }^{5}$ high-density arrays ${ }^{6,7}$ and drug delivery ${ }^{8-10}$ It is well-known that the self-assembly of diblock copolymers in the solid state can result in a wide range of morphologies. ${ }^{711-15}$ Similarly, diblock copolymers can self-assemble in solution when the solvent is selective for one of the two blocks. In this case, the final morphology depends on the relative volume fractions of each block, ${ }^{16}$ the selectivity of the solvent(s) for each block, ${ }^{17}$ and the copolymer concentration. ${ }^{18,19}$ It is welldocumented that the three main copolymer morphologies formed in solution are spheres, ${ }^{16}$ worms ${ }^{19,20}$ and vesicles ${ }^{21}$ but

\footnotetext{
${ }^{a}$ Department of Chemistry, University of Sheffield, Dainton Building, Brook Hill, Sheffield, South Yorkshire, S3 7HF, UK. E-mail: s.p.armes@sheffield.ac.uk

${ }^{b} B A S F$ SE, GMV/P-B001, 67056 Ludwigshafen, Germany

$\dagger$ Electronic supplementary information (ESI) available: Materials and methods, polymer characterization techniques, SAXS models, supporting figures: GPC chromatograms, assigned ${ }^{1} \mathrm{H}$ NMR spectra, calibration plot for determining the mean DP of the PDMAC precursor, temperature-dependent rheological studies, SIPLI rheology data, full spectra for the variable temperature ${ }^{1} \mathrm{H}$ NMR spectroscopy study, apparent $z$-average diameter as a function of temperature as determined by DLS studies and apparent $z$-average diameter as a function of $\mathrm{pH}$ as determined by DLS studies. See DOI: $10.1039 / \mathrm{c} 9 \mathrm{sc} 04197 \mathrm{~d}$
}

other morphologies such as rods,,$^{22-24}$ toroids $^{25}$ and lamellae ${ }^{26}$ have also been reported.

Traditionally, block copolymer self-assembly in solution has been achieved via various post-polymerization processing strategies. ${ }^{16,20-23}$ However, over the past decade increasing attention has been paid to polymerization-induced selfassembly (PISA). ${ }^{19,24,27-30}$ Most PISA syntheses reported in the literature are based on reversible addition-fragmentation chain transfer (RAFT) polymerization..$^{29,31-44}$ The versatility of this radical-based chemistry has enabled the convenient preparation of a wide range of well-defined functional block copolymers in the form of concentrated dispersions. ${ }^{27-29}$ More specifically, PISA syntheses based on RAFT dispersion polymerization has enabled the synthesis of diblock copolymer nano-objects that can exhibit thermoresponsive behavior. ${ }^{1945-50}$ For example, cooling an aqueous amphiphilic diblock copolymer worm gel below ambient temperature induces a worm-to-sphere transition (and concomitant degelation). ${ }^{19}$ Alternatively, heating the analogous hydrophobic copolymer worms in non-aqueous media can induce the same change in copolymer morphology. ${ }^{48}$ In each case, this change in morphology can be rationalized in terms of surface plasticization of the nanoobjects by solvent molecules, which leads to a subtle change in the fractional packing parameter for the copolymer chains. ${ }^{51-53}$ There have been a couple of reports of diblock copolymers that can form more than one morphology in a given solven $t^{18}$ or a binary mixture of solvents under certain conditions. ${ }^{17}$ However, as far as we are aware, there have been no 
reports of a single (i.e. fixed composition) diblock copolymer in any solvent that is capable of crossing three phase boundaries to form spheres, worms, vesicles or lamellae.

Such rich phase behavior is demonstrated herein for a new poly( $N, N$-dimethylacrylamide)-block-poly(4-hydroxybutyl acrylate-stat-diacetone acrylamide) [PDMAC-P(HBA-stat-DAAM)] amphiphilic diblock copolymer that is prepared directly in water under mild conditions (see Fig. 1). The sphere/worm and worm/vesicle phase transitions can be achieved by simply varying the temperature of the resulting aqueous copolymer dispersion and proceed both rapidly and reversibly even when conducted at copolymer concentrations as low as $0.10 \% \mathrm{w} / \mathrm{w}$. Moreover, a vesicle-to-lamellae transition is also observed for this system, although this latter thermal transition is characterized by significant hysteresis during the cooling cycle.

\section{Results and discussion}

The diblock copolymer used in this study was prepared via PISA using a highly convenient one-pot RAFT aqueous dispersion polymerization formulation (Fig. 1a). First, $N, N^{\prime}$-dimethylacrylamide (DMAC) was polymerized in an $80 \% \mathrm{w} / \mathrm{w}$ aqueous solution at $30{ }^{\circ} \mathrm{C}$ using a trithiocarbonate-based RAFT agent combined with a low-temperature redox initiator. The initial highly concentrated aqueous solution was required to ensure solubility of the RAFT agent. After $30 \mathrm{~min}$, the reaction mixture was diluted to $20 \% \mathrm{w} / \mathrm{w}$ in order to lower its solution viscosity. After $4 \mathrm{~h}$, a small aliquot of the resulting water-soluble PDMAC precursor was removed for analysis. Gel permeation chromatography (GPC; DMF eluent, $60{ }^{\circ} \mathrm{C}$ ) analysis indicated a relatively narrow molecular weight distribution $\left(M_{\mathrm{w}} / M_{\mathrm{n}}=1.23\right.$, see Fig. 1b) while ${ }^{1} \mathrm{H}$ NMR spectroscopy studies confirmed that more than 99\% DMAC conversion had been achieved (Fig. S1, ESI $\dagger$ ). The mean degree of polymerization (DP) of this PDMAC precursor was determined to be 56 by end-group analysis using UV spectroscopy (see Fig. S2, ESI $\dagger$ ).

This PDMAC F6 $_{6}$ precursor was then chain-extended in situ by statistical copolymerization of a mixture of 4-hydroxybutyl acrylate (HBA; $80 \mathrm{~mol} \%$ ) and diacetone acrylamide (DAAM; $20 \mathrm{~mol} \%$ ) at $20 \% \mathrm{w} / \mathrm{w}$ solids to produce a PDMAC ${ }_{56}-\mathrm{P}$ (HBA-statDAAM) $)_{264}$ diblock copolymer, where the subscripts refer to the mean DPs of each block. GPC analysis indicated efficient chain extension and a relatively narrow molecular weight distribution $\left(M_{\mathrm{w}} / M_{\mathrm{n}}<1.20\right)$ for the final diblock copolymer (see Fig. $1 \mathrm{~b}$ ). ${ }^{1} \mathrm{H}$ NMR spectroscopy studies confirmed essentially full conversion for the HBA and DAAM comonomers (>99\%; see Fig. S1, ESI $\dagger$ ) and also that the expected composition for the core-forming $\mathrm{P}$ (HBA-stat-DAAM $)_{264}$ block (78 $\left.\pm 2 \mathrm{~mol} \% \mathrm{HBA}\right)$ was obtained within experimental error.

Recent in silico studies and preliminary experimental data suggest that HBA should be a suitable core-forming block for aqueous PISA. ${ }^{54}$ Indeed, the $20 \% \mathrm{w} / \mathrm{w}$ dispersion of PDMAC $_{56^{-}}$ $\mathrm{P}(\text { HBA-stat-DAAM })_{264}$ diblock copolymer nano-objects prepared herein formed a free-standing gel at $25^{\circ} \mathrm{C}$ (Fig. 2). On cooling to $1{ }^{\circ} \mathrm{C}$, degelation occurred to produce a transparent free-flowing dispersion. On heating to $50{ }^{\circ} \mathrm{C}$, a turbid, free-flowing dispersion was formed, while a turbid paste was formed at $70{ }^{\circ} \mathrm{C}$. To a
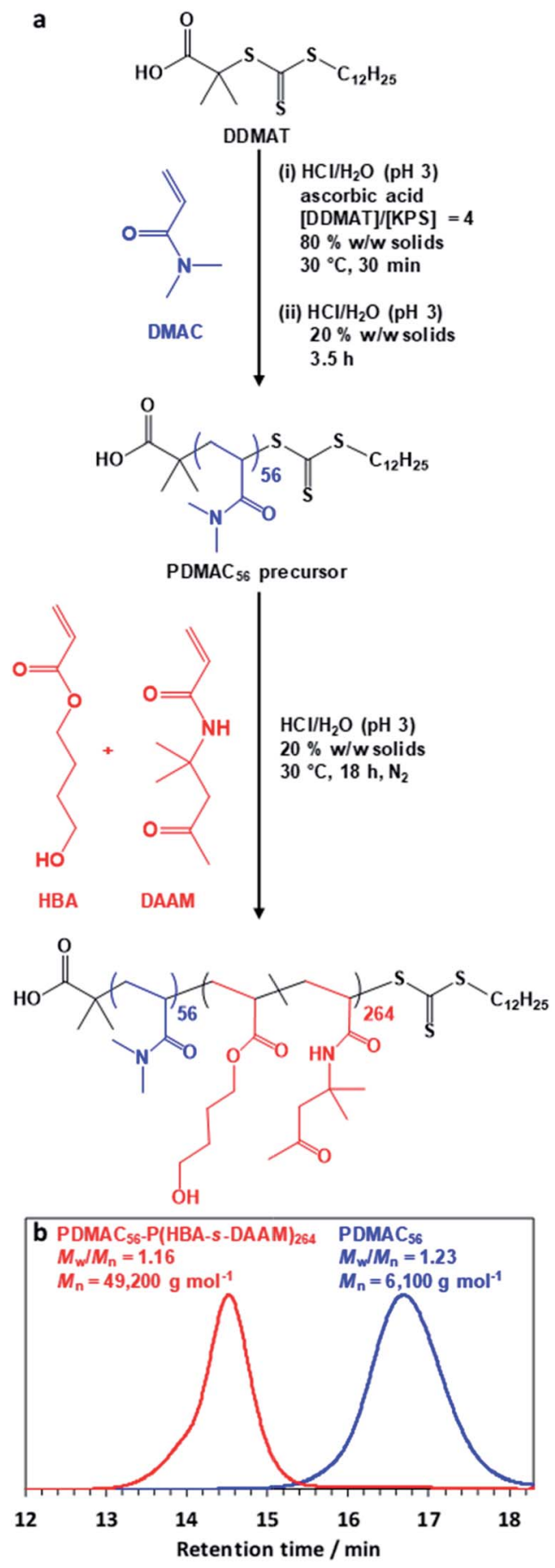

Fig. 1 (a) Block copolymer synthesis via polymerization-induced selfassembly (PISA). Reaction scheme for the synthesis of the PDMAC 56 precursor via RAFT solution polymerization of DMAC at $30{ }^{\circ} \mathrm{C}$ using a DDMAT chain transfer agent and a redox initiator [potassium persulfate (KPS) plus ascorbic acid]. Subsequent PDMAC 56 chain extension with a binary mixture of HBA ( $80 \mathrm{~mol} \%)$ and DAAM (20 mol\%) via RAFT aqueous dispersion copolymerization at $\mathrm{pH} 3$ produced a welldefined PDMAC $56-P(H B A-s t a t-D A A M)_{264}$ diblock copolymer. (b) DMF GPC data obtained for the PDMAC 56 precursor and final PDMAC ${ }_{56}$ $\mathrm{P}(\mathrm{HBA}$-stat-DAAM) 264 diblock copolymer (refractive index detector; expressed relative to a series of poly(methyl methacrylate) calibration standards). 


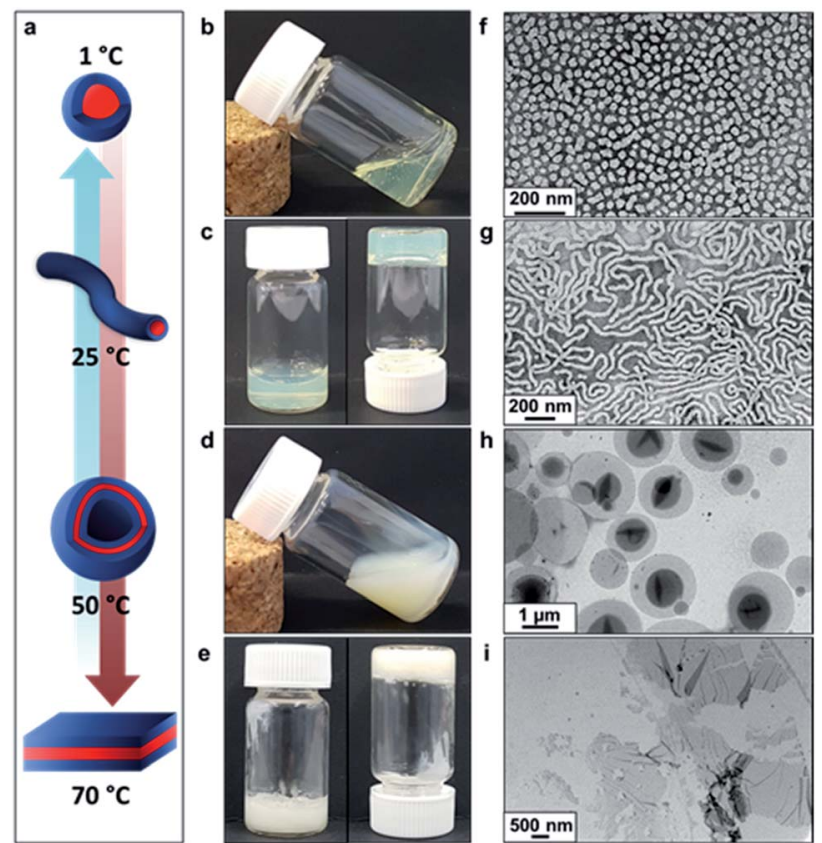

Fig. 2 Thermally-induced diblock copolymer morphology transitions in aqueous solution. (a) Schematic representation of the reversible morphological transitions that occur for a $20 \% \mathrm{w} / \mathrm{w}$ aqueous dispersion of PDMAC $_{56}-\mathrm{P}(\mathrm{HBA}-$ stat-DAAM) 264 diblock copolymer nanoobjects on varying the temperature from $1^{\circ}$ to $70{ }^{\circ} \mathrm{C}$. Digital images show the physical appearance of this aqueous dispersion: (b) on cooling to $1{ }^{\circ} \mathrm{C}$ for $30 \mathrm{~min}$, (c) at ambient temperature $\left(25^{\circ} \mathrm{C}\right)$, (d) on heating to $50{ }^{\circ} \mathrm{C}$ for $30 \mathrm{~min}$ and (e) on heating to $70^{\circ} \mathrm{C}$ for $30 \mathrm{~min}$. TEM images recorded for $0.10 \% \mathrm{w} / \mathrm{w}$ aqueous dispersions of $\mathrm{PDMAC}_{56}-$ $\mathrm{P}(\mathrm{HBA} \text {-stat-DAAM })_{264}$ using uranyl formate as a negative stain after covalent stabilization at the desired temperature using adipic acid dihydrazide $(\mathrm{ADH})$ at a DAAM/ADH molar ratio of 1.0: (f) spheres (crosslinked at $1{ }^{\circ} \mathrm{C}$ ), (g) worms (crosslinked at $25^{\circ} \mathrm{C}$ ), (h) vesicles (crosslinked at $50^{\circ} \mathrm{C}$ ) and (i) lamellae (crosslinked at $70^{\circ} \mathrm{C}$ ).

examine the copolymer morphologies associated with these thermal transitions, transmission electron microscopy (TEM) studies were performed on the PDMAC $_{56}-\mathrm{P}(\mathrm{HBA} \text {-stat-DAAM })_{264}$ diblock copolymer nano-objects. Crosslinking of the P(HBA-statDAAM) $)_{264}$ block was conducted at the desired temperature using adipic acid dihydrazide (ADH) at $\mathrm{pH} 3$, as previously reported for PDMAC-PDAAM diblock copolymer nano-objects. ${ }^{55}$ Such covalent stabilization was essential to obtain high-quality images: in the absence of any cross-linking, the relatively low glass transition temperature of the core-forming block simply led to film formation on the TEM grid. Moreover, crosslinking also eliminated the thermoresponsive behavior of this diblock copolymer, hence preserving the copolymer morphology at any desired temperature. Thus this cross-linking protocol enabled visualization of pure spheres, worms, vesicles or lamellae after covalent stabilization at $1,25,50$ or $70{ }^{\circ} \mathrm{C}$, respectively (Fig. $2 \mathrm{f}-\mathrm{i}$ ).

Rheology studies were conducted on a $20 \% \mathrm{w} / \mathrm{w}$ aqueous dispersion of the linear (i.e. non-crosslinked) PDMAC $_{56}-\mathrm{P}(\mathrm{HBA}-$ stat-DAAM) $)_{264}$ nano-objects as a function of temperature (Fig. 3 and S3, ESI†). As expected, a low-viscosity fluid was formed at $1{ }^{\circ} \mathrm{C}$ owing to the presence of free-flowing spherical nanoobjects. Warming to ambient temperature induced a sol-gel
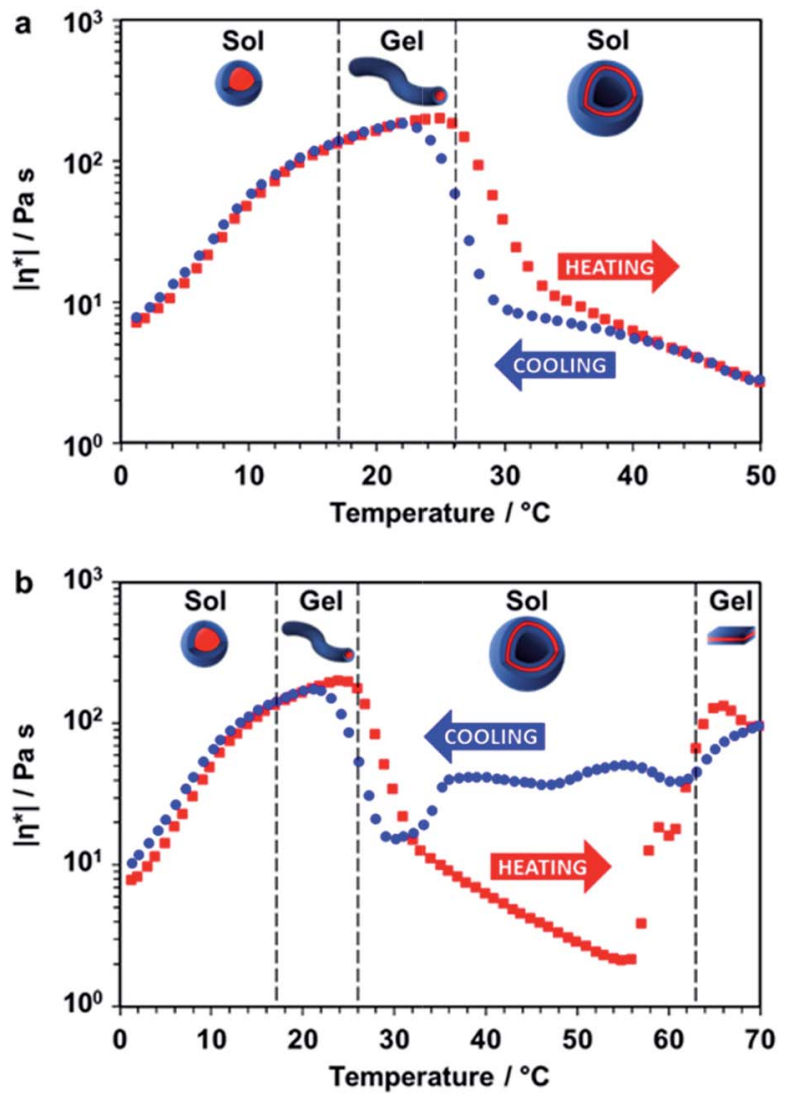

Fig. 3 Thermally-induced change in complex viscosity for an aqueous dispersion of linear diblock copolymer nano-objects. Temperaturedependent rheological studies for a $20 \% \mathrm{w} / \mathrm{w}$ aqueous dispersion of PDMAC $_{56}-\mathrm{P}(\mathrm{HBA}$-stat-DAAM) 264 nano-objects at an applied strain of $1.0 \%$ and an angular frequency of $1.0 \mathrm{rad} \mathrm{s}^{-1}$. The dispersion was equilibrated at $1{ }^{\circ} \mathrm{C}$ for 15 min prior to heating. The black dashed lines indicate the sol-gel transitions observed on heating as determined from the $G^{\prime}$ and $G^{\prime \prime}$ values (Fig. S3, ESI†). (a) Complex viscosity $\left(\left|\eta^{*}\right|\right)$ vs. temperature data obtained for a thermal cycle from $1{ }^{\circ} \mathrm{C}$ to $50^{\circ} \mathrm{C}$ to $1{ }^{\circ} \mathrm{C}$ at a heating/cooling rate of $1{ }^{\circ} \mathrm{C} \min ^{-1}[\mathbf{a}$ heating curve, cooling curve]. (b) Complex viscosity vs. temperature data for a thermal cycle over an expanded temperature range of $1{ }^{\circ} \mathrm{C}$ to $70^{\circ} \mathrm{C}$ to $1^{\circ} \mathrm{C}$ at a heating/cooling rate of $1^{\circ} \mathrm{C} \min ^{-1}[\mathbf{\square}$ heating curve, cooling curve].

transition, producing a soft, transparent free-standing gel. This indicates the formation of highly anisotropic worms, with multiple inter-particle contacts producing a 3D network. ${ }^{56}$ The storage modulus $\left(G^{\prime}\right)$ exceeds the loss modulus $\left(G^{\prime \prime}\right)$ at $17^{\circ} \mathrm{C}$, which corresponds to the critical gelation temperature (CGT) (Fig. S3, ESI, $\uparrow$ for $G^{\prime}$ and $G^{\prime \prime}$ data). A maximum gel viscosity was observed at $25{ }^{\circ} \mathrm{C}$. Further heating led to a significant reduction in viscosity (and a concomitant increase in turbidity) owing to the formation of vesicles. These sphere-to-worm and worm-tovesicle transitions proved to be remarkably reversible, with relatively little hysteresis being observed at heating/cooling rates of $1{ }^{\circ} \mathrm{C} \mathrm{min}^{-1}$ (Fig. 3a). Heating the turbid, free-flowing vesicular dispersion above $50{ }^{\circ} \mathrm{C}$ initially caused a further reduction in the complex viscosity (see Fig. 3b). However, the dispersion became a turbid paste between $63{ }^{\circ} \mathrm{C}$ and $70{ }^{\circ} \mathrm{C}$ and the complex viscosity increased by approximately two orders of 
magnitude, which corresponds to the formation of lamellae (see Fig. 2i). Significant hysteresis was observed for the lamellae-tovesicle transition on cooling, but good reversibility was observed below approximately $22{ }^{\circ} \mathrm{C}$.

Further evidence for these four types of diblock copolymer nano-objects was obtained using shear-induced polarized light imaging (SIPLI), see Fig. S4. $\dagger$ This opto-rheological technique has been recently used to demonstrate the alignment of anisotropic nano-objects such as block copolymer worms and lamellae at a certain critical rate of applied shear. ${ }^{57}$ Thus, the SIPLI image recorded under continuous shear flow at $3{ }^{\circ} \mathrm{C}$ appears dark (see Fig. S4 $\dagger$ ); this is consistent with the presence of isotropic spheres, which cannot be aligned. A characteristic Maltese cross is observed under this shear flow at approximately $20{ }^{\circ} \mathrm{C}$, indicating the formation (and shear-induced alignment) of highly anisotropic worms. This distinctive pattern disappears at $33^{\circ} \mathrm{C}$ owing to the formation of isotropic vesicles while a new Maltese cross (with associated multiple colors arising from strong birefringence) is obtained at $45{ }^{\circ} \mathrm{C}$. The latter feature indicates the presence of anisotropic lamellae that have either a perpendicular (with the lamellar normal parallel to the neutral direction of the flow) or transverse (with the lamellar normal parallel to the velocity direction of the flow) orientation. ${ }^{58}$ [N.B. The above characteristic temperatures required to induce formation of block copolymer worms, vesicles and lamellae do not match those indicated by the oscillatory rheology data shown in Fig. 3. This is because the applied (continuous) shear is significantly greater in the latter case, which promotes the formation of worms, vesicles and lamellae under milder conditions, i.e. lower temperatures].

Small-angle X-ray scattering (SAXS) studies were conducted on a $1.0 \% \mathrm{w} / \mathrm{w}$ aqueous dispersion of linear $\mathrm{PDMAC}_{56} \mathrm{P}(\mathrm{HBA}-$ stat-DAAM $)_{264}$ nano-objects as a function of temperature at $\mathrm{pH} 3$ (Fig. 4). The gradient in the low $q$ region of an $I(q) v s . q$ plot (where $I(q)$ is the scattering intensity and $q$ is the scattering vector) is characteristic of the predominant copolymer morphology. ${ }^{59}$ This gradient is close to zero at $1{ }^{\circ} \mathrm{C}$, which suggests the presence of spheres. At $25{ }^{\circ} \mathrm{C}$, the gradient shifts towards -1 , indicating the formation of highly anisotropic worms. ${ }^{19,48}$ On raising the temperature to $50{ }^{\circ} \mathrm{C}$, the low $q$ gradient increases to -2 , which is characteristic of bilayer (or vesicle) formation. At $70{ }^{\circ} \mathrm{C}$, the diffraction peak observed at $q=$ $0.019 \AA^{-1}$ suggests stacked lamellae sheets (see Fig. 4a, black arrow). Analysis of the SAXS data shown in Fig. 4a indicated a core diameter of $22.8 \mathrm{~nm}$ for the spheres, which is consistent with an overall hydrodynamic DLS diameter of $33 \mathrm{~nm}$ recorded at the same temperature. A core cross-section diameter of $23.0 \mathrm{~nm}$ was determined for the worms; this is consistent with TEM studies $(26 \pm 3 \mathrm{~nm})$ if the highly deformable nature of the core-forming block is taken into consideration. The mean vesicle membrane thickness was $17.2 \mathrm{~nm}$, which indicates significant inter-digitation of the structure-directing hydrophobic $\mathrm{P}(\mathrm{HBA}-\text { stat-DAAM })_{264}$ chains. $^{60}$

Finally, the mean distance between the stacked lamellae sheets was determined to be $33 \mathrm{~nm}$ as calculated from the diffraction peak observed at $q=0.019 \AA^{-1}$. Fig. 4b shows 2D SAXS patterns recorded under applied shear and also at zero
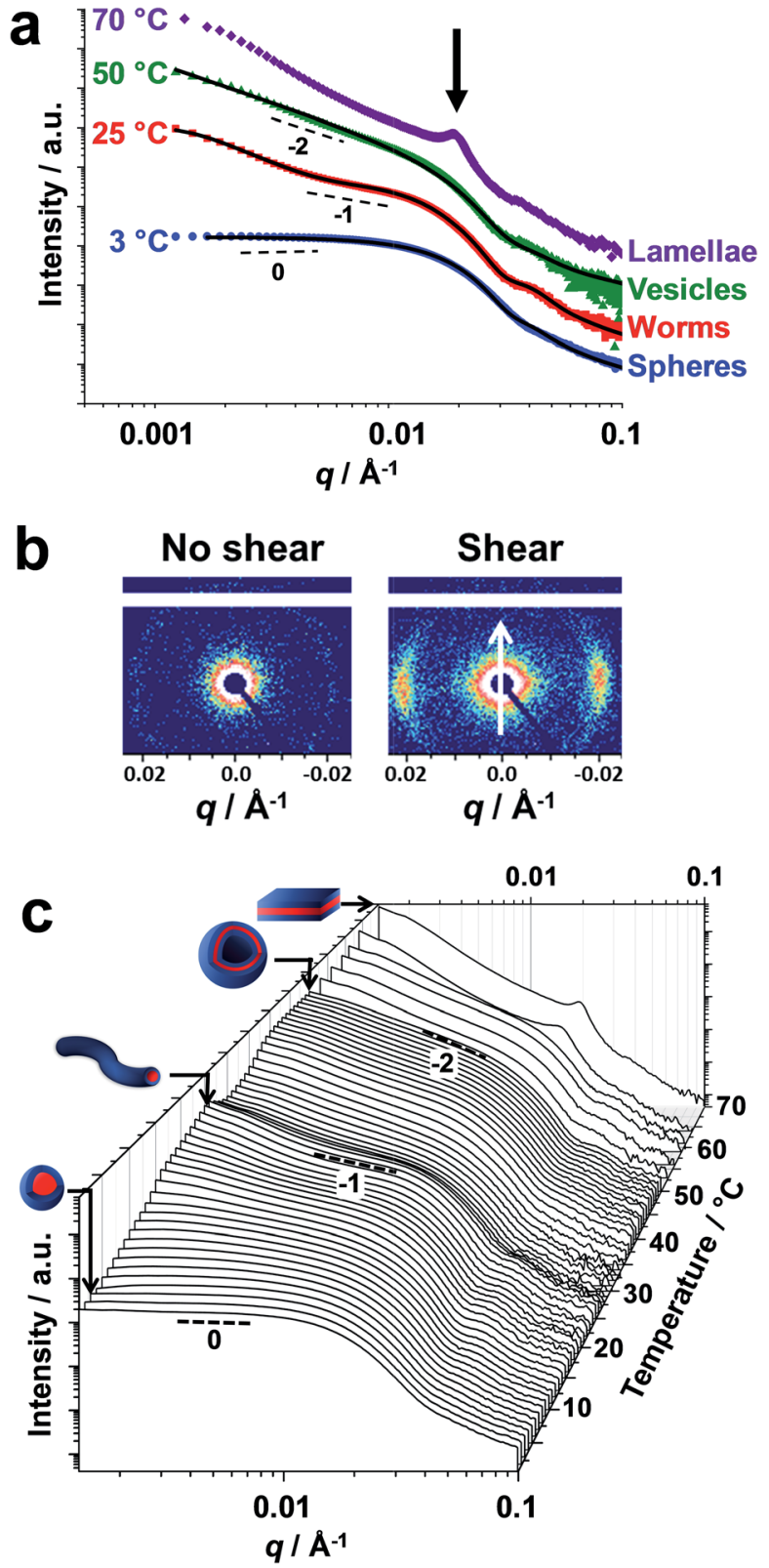

Fig. 4 Small-angle X-ray scattering studies of linear diblock copolymer nano-objects. (a) Double-logarithmic plot of SAXS patterns recorded for a $1.0 \% \mathrm{w} / \mathrm{w}$ aqueous dispersion of thermoresponsive $\mathrm{PDMAC}_{56}-\mathrm{P}(\mathrm{HBA}-$ stat-DAAM) 264 nano-objects at $3{ }^{\circ} \mathrm{C}$ (blue data), $25^{\circ} \mathrm{C}$ (red data), $50{ }^{\circ} \mathrm{C}$ (green data) and $70{ }^{\circ} \mathrm{C}$ (purple data). The black lines indicate the data fits obtained using appropriate scattering models. For guidance, black dashed lines indicate zero, -1 and -2 gradients, while the blue, green and purple data sets are offset by arbitrary factors to aid clarity. (b) 2D SAXS patterns recorded either at zero shear or under applied shear (direction indicated by the white arrow) during rheo-SAXS experiments conducted on a $20 \%$ $\mathrm{w} / \mathrm{w}$ aqueous dispersion of $\mathrm{PDMAC}_{56}-\mathrm{P}(\mathrm{HBA}-$-stat-DAAM) 264 nanoobjects at $63{ }^{\circ} \mathrm{C}$. (c) SAXS patterns recorded for a $1.0 \% \mathrm{w} / \mathrm{W}$ aqueous dispersion of thermoresponsive PDMAC ${ }_{56}-\mathrm{P}\left(\mathrm{HBA}-\mathrm{stat}^{-D A A M}\right)_{264}$ nanoobjects between 1 and $70{ }^{\circ} \mathrm{C}$ using a heating rate of $1{ }^{\circ} \mathrm{C} \mathrm{min}-1$. For guidance, black dashed lines indicate zero, -1 and -2 gradients.

shear during rheo-SAXS experiments conducted at $63{ }^{\circ} \mathrm{C}$ (see ESI $\dagger$ for further details). The distinctly anisotropic pattern obtained under applied shear clearly indicates the presence of 
lamellae in a perpendicular orientation. ${ }^{58}$ Fig. $4 \mathrm{c}$ shows a series of SAXS patterns recorded for a $1.0 \% \mathrm{w} / \mathrm{w}$ aqueous dispersion of PDMAC $_{56}-\mathrm{P}(\mathrm{HBA} \text {-stat-DAAM })_{264}$ nano-objects on heating from $1{ }^{\circ} \mathrm{C}$ to $70{ }^{\circ} \mathrm{C}$ at a heating rate of $1{ }^{\circ} \mathrm{C} \mathrm{min}^{-1}$. Clearly, there is a gradual increase in the low $q$ gradient as the initial spheres are converted into first worms and then vesicles. The diffraction peak assigned to stacked lamellae is observed at $64{ }^{\circ} \mathrm{C}$ and $70{ }^{\circ} \mathrm{C}$ (Fig. 4c). This data set confirms that the interconversion between these four copolymer morphologies occurs rapidly on relatively short time scales, even at rather low copolymer concentration. In summary, the TEM images (Fig. 2), oscillatory rheology studies (Fig. 3), SIPLI measurements (Fig. S4†) and SAXS experiments (Fig. 4) provide compelling evidence for interconversion between spheres, worms, vesicles and lamellae for this PDMAC $_{56}-\mathrm{P}(\mathrm{HBA} \text {-stat-DAAM })_{264}$ diblock copolymer. Variable temperature ${ }^{1} \mathrm{H}$ NMR spectroscopy studies were conducted to examine the mechanism for this unique thermoresponsive behavior. Accordingly, a $20 \% \mathrm{w} / \mathrm{w}$ aqueous copolymer dispersion was heated from $5{ }^{\circ} \mathrm{C}$ to $70{ }^{\circ} \mathrm{C}$ with spectra being recorded at $5{ }^{\circ} \mathrm{C}$ intervals and normalized relative to an external standard (pyridine). Partial ${ }^{1} \mathrm{H}$ NMR spectra are shown in Fig. 5 (see Fig. S5, ESI, $\uparrow$ for the full spectra). ${ }^{1} \mathrm{H}$ NMR signals assigned to the core-forming $\mathrm{P}(\mathrm{HBA}-\text { stat-DAAM })_{264}$ chains become more prominent at higher temperature, indicating progressively greater hydration for this weakly hydrophobic structuredirecting block (Fig. 5a). Such spectral changes can be quantified by normalizing the integrated intensity of the two $\mathrm{CH}_{2}-\mathrm{OH}$ protons assigned to the HBA repeat units relative to that of the external standard. This approach enables the apparent degree of hydration of the HBA repeat units within the $\mathrm{P}$ (HBA-statDAAM $)_{264}$ core-forming block to be calculated at any given temperature. This parameter is expressed as a percentage of the maximum value determined by ${ }^{1} \mathrm{H}$ NMR spectroscopy using $\mathrm{CD}_{3} \mathrm{OD}$ (the PDMAC ${ }_{56}-\mathrm{P}(\mathrm{HBA}-\text { stat-DAAM) })_{264}$ chains are molecularly dissolved in this solvent); it increases from $62 \%$ to $83 \%$ on heating a $20 \% \mathrm{w} / \mathrm{w}$ aqueous copolymer dispersion from $5{ }^{\circ} \mathrm{C}$ to $70{ }^{\circ} \mathrm{C}$ (Fig. $5 \mathrm{~b}$ ).

Clearly, the $\mathrm{P}(\mathrm{HBA}-\text { stat-DAAM })_{264}$ block is partially hydrated at all temperatures and its degree of hydration increases at higher temperature. This is attributed to the temperature dependence of the Flory-Huggins $\chi$ parameter for the interaction between the $\mathrm{P}(\mathrm{HBA}-\text { stat-DAAM })_{264}$ chains and water. As this hydrophobic block becomes progressively more hydrated, its volume fraction increases relative to that of the hydrophilic PDMAC stabilizer block. This leads to a subtle increase in the fractional packing parameter, $P$, for the copolymer chains, ${ }^{51,52}$ which accounts for the evolution in morphology from spheres to worms to vesicles to lamellae that is observed on heating. These morphological transitions are ultimately reversible on cooling, although significant hysteresis is observed for the initial lamellae-to-vesicle transformation (see Fig. 3b). Interestingly, similar thermoresponsive behavior has been recently predicted for a single diblock copolymer composition by Borisov and co-workers. ${ }^{61}$

Dynamic light scattering (DLS) was used to determine the sphere-equivalent diameter for a $0.10 \% \mathrm{w} / \mathrm{w} \mathrm{PDMAC}_{56}-\mathrm{P}(\mathrm{HBA}-$ stat-DAAM $)_{264}$ aqueous dispersion during a thermal cycle from $2{ }^{\circ} \mathrm{C}$ to $50{ }^{\circ} \mathrm{C}$ to $2{ }^{\circ} \mathrm{C}$ (Fig. S6, ESI $\dagger$ ). These DLS data suggest that
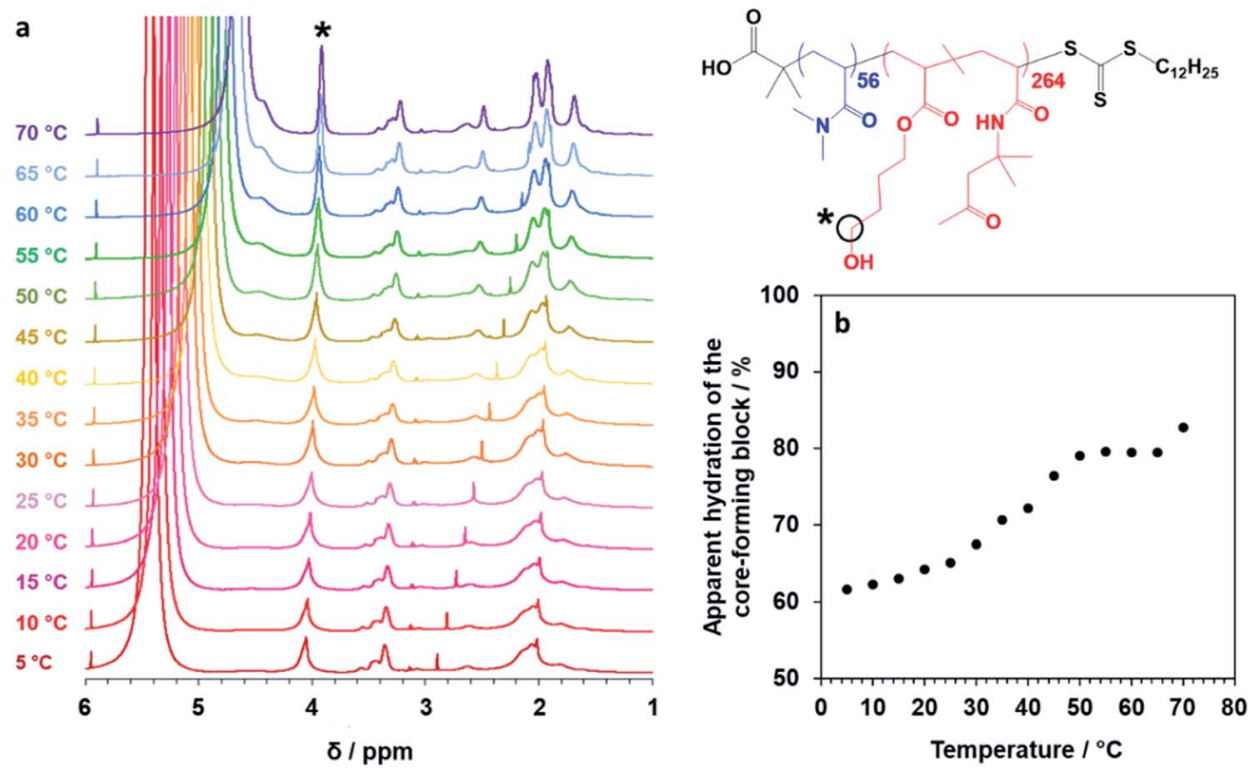

Fig. 5 Variable temperature NMR studies of linear thermoresponsive diblock copolymer nano-objects. (a) Normalized ${ }^{1} \mathrm{H}$ NMR spectra recorded for a $20 \% \mathrm{w} / \mathrm{w}$ aqueous dispersion of PDMAC ${ }_{56}-\mathrm{P}\left(\mathrm{HBA}\right.$-stat-DAAM) 264 nano-objects on heating from $5{ }^{\circ} \mathrm{C}$ to $70{ }^{\circ} \mathrm{C}$. For clarity, only partial spectra in the 1-6 ppm range are shown (see Fig. S5, ESI, $\uparrow$ for the full spectra). The signal marked with an asterisk is assigned to the two $\mathrm{CH}_{2}-\mathrm{OH}$ protons on the HBA residues: the gradual increase in its intensity on heating indicates progressively greater hydration of the core-forming block at higher temperature. (b) Apparent degree of hydration of the hydrophobic P(HBA-stat-DAAM) 264 block as a function of temperature (with $100 \%$ hydration corresponding to the true composition of this structure-directing block, as calculated by ${ }^{1} \mathrm{H}$ NMR spectroscopy studies of the molecularly-dissolved copolymer chains in $\mathrm{CD}_{3} \mathrm{OD}$ ). 
both the sphere-to-worm and worm-to-vesicle thermal transitions occur rapidly and reversibly, with minimal hysteresis being observed even at copolymer concentrations as low as $0.10 \% \mathrm{w} / \mathrm{w}$. The excellent reversibility observed under such conditions is attributed to the relatively high mobility of the acrylic-rich core-forming block, which has a relatively low glass transition temperature.

Finally, raising the solution $\mathrm{pH}$ from $\mathrm{pH} 3$ to $\mathrm{pH} 7$ at $20{ }^{\circ} \mathrm{C}$ causes a reversible reduction in the sphere-equivalent particle diameter from $333 \mathrm{~nm}$ (worms) to $38 \mathrm{~nm}$ (spheres) as judged by DLS (see Fig. S7, ESI $\dagger$ ). This morphological transition is attributed to end-group ionization owing to deprotonation of the single carboxylic acid group located at the end of each PDMAC steric stabilizer block. ${ }^{62}$ Thus this remarkable thermoresponsive diblock copolymer also exhibits $\mathrm{pH}$-responsive behavior.

\section{Conclusions}

In summary, we report the one-pot PISA synthesis of a new amphiphilic PDMAC $_{56}-\mathrm{P}(\mathrm{HBA} \text {-stat-DAAM })_{264}$ diblock copolymer that can form spheres, worms or vesicles rapidly and reversibly in aqueous solution at copolymer concentrations as low as $0.10 \% \mathrm{w} / \mathrm{w}$. In addition, a vesicle-to-lamellae transition also occurs on heating to around $70{ }^{\circ} \mathrm{C}$, but the complementary lamellae-to-vesicle transition suffers from significant hysteresis on cooling. This new system is expected to provide a suitable model for studying the kinetics and mechanism(s) of block copolymer self-assembly in solution, as well as offering a highly convenient model system for theoretical studies of thermoresponsive block copolymer nano-objects. ${ }^{63}$ In addition, the excellent thermoreversibility exhibited by this new system is expected to facilitate the in situ loading of vesicles with either nanoparticles or globular proteins/enzymes, with subsequent release of such payloads being feasible simply by lowering the solution temperature to induce a vesicle-to-worm (or vesicle-tosphere) morphological transition.

\section{Conflicts of interest}

There are no conflicts to declare.

\section{Acknowledgements}

We thank EPSRC (EP/L016281) for a CDT PhD studentship for S. J. B. and BASF SE (Ludwigshafen, Germany) for partial funding of this project. S. P. A. thanks EPSRC for a Particle Technology Fellowship (EP/R003009). BASF SE is also thanked for permission to publish this work. We are grateful to the European Synchrotron Radiation Facility (ESRF) for providing synchrotron beam-time (SC-4601, SC-4864) and thank Dr T. Zinn and the personnel of ID02 for their assistance. Scott Bader Ltd. is thanked for supplying the HBA monomer. O. O. M. and S. P. A. thank EPSRC for a capital equipment grant to purchase the Xenocs Xeuss 2.0/Excillum SAXS instrument used to perform the rheo-SAXS experiments (EP/M028437/1).

\section{Notes and references}

1 A. V. Ruzette and L. Leibler, Nat. Mater., 2005, 4, 19-31.

2 M. Seo and M. A. Hillmyer, Science, 2012, 336, 1422-1426.

3 P. M. Lipic, F. S. Bates and M. A. Hillmyer, J. Am. Chem. Soc., 1998, 120, 8963-8970.

4 H. Ahn, S. Park, S.-W. Kim, P. J. Yoo, D. Y. Ryu and T. P. Russell, ACS Nano, 2014, 8, 11745-11752.

5 C. Tang, E. M. Lennon, G. H. Fredrickson, E. J. Kramer and C. J. Hawker, Science, 2008, 322, 429-433.

6 S. Ouk Kim, H. H. Solak, M. P. Stoykovich, N. J. Ferrier, J. J. de Pablo and P. F. Nealey, Nature, 2003, 424, 411-414.

7 S. H. Kim, M. J. Misner, T. Xu, M. Kimura and T. P. Russell, Adv. Mater., 2004, 16, 226-231.

8 S. W. Kim, B. Jeong, Y. H. Bae and D. S. Lee, Nature, 1997, 388, 860-862.

9 A. P. Nowak, V. Breedveld, L. Pakstis, B. Ozbas, D. J. Pine, D. Pochan and T. J. Deming, Nature, 2002, 417, 424-428.

10 Y. A. N. Geng, P. Dalhaimer, S. Cai, R. Tsai, T. Minko and D. E. Discher, Nat. Nanotechnol., 2007, 2, 249-255.

11 J. T. Chen, E. L. Thomas, C. K. Ober and G. Mao, Science, 1996, 273, 343-346.

12 F. S. Bates, Science, 1991, 251, 898-905.

13 L. Leibler, Macromolecules, 1980, 13, 1602-1617.

14 A. K. Khandpur, S. Ftirster, F. S. Bates, I. W. Hamley, A. J. Ryan, W. Bras, K. Almdal and K. Mortensen, Macromolecules, 1995, 28, 8796-8806.

15 M. W. Matsen and F. S. Bates, Macromolecules, 1996, 29, 1091-1098.

16 L. Zhang and A. Eisenberg, Science, 1995, 268, 1728-1731.

17 S. Abbas, Z. Li, H. Hassan and T. P. Lodge, Macromolecules, 2007, 40, 4048-4052.

18 S. Y. Kim, K. E. Lee, S. S. Han and B. Jeong, J. Phys. Chem. B, 2008, 112, 7420-7423.

19 A. Blanazs, R. Verber, O. O. Mykhaylyk, A. J. Ryan, J. Z. Heath, C. W. I. Douglas and S. P. Armes, J. Am. Chem. Soc., 2012, 134, 9741-9748.

20 Y.-Y. Won, H. T. Davis and F. S. Bates, Science, 1999, 283, 960-963.

21 B. M. Discher, Y. Won, D. S. Ege, J. C.-M. Lee, F. S. Bates, D. E. Discher and D. A. Hammer, Science, 1999, 284, 1143-1146.

22 X. Wang, G. Guerin, H. Wang, Y. Wang, I. Manners and M. A. Winnik, Science, 2007, 317, 644-647.

23 J. B. Gilroy, T. Gädt, G. R. Whittell, L. Chabanne, J. M. Mitchels, R. M. Richardson, M. A. Winnik and I. Manners, Nat. Chem., 2010, 2, 566-570.

24 C. E. Boott, J. Gwyther, R. L. Harniman, D. W. Hayward and I. Manners, Nat. Chem., 2017, 9, 785-792.

25 D. J. Pochan, Z. Chen, H. Cui, K. Hales, K. Qi and K. L. Wooley, Science, 2004, 306, 94-97.

26 P. Yang, L. P. D. Ratcliffe and S. P. Armes, Macromolecules, 2013, 46, 8545-8556.

27 S. L. Canning, G. N. Smith and S. P. Armes, Macromolecules, 2016, 49, 1985-2001.

28 N. J. Warren and S. P. Armes, J. Am. Chem. Soc., 2014, 136, 10174-10185. 
29 B. Charleux, G. Delaittre, J. Rieger and F. D'Agosto, Macromolecules, 2012, 45, 6753-6765.

30 J. Rieger, Macromol. Rapid Commun., 2015, 36, 1458-1471.

31 J. Chiefari, Y. K. B. Chong, F. Ercole, J. Krstina, J. Jeffery, T. P. T. Le, R. T. A. Mayadunne, G. F. Meijs, C. L. Moad, G. Moad, E. Rizzardo and S. H. Thang, Macromolecules, 1998, 31, 5559-5562.

32 S. Sugihara, A. H. Ma'Radzi, S. Ida, S. Irie, T. Kikukawa and Y. Maeda, Polymer, 2015, 76, 17-24.

33 S. Perrier, Macromolecules, 2017, 50, 7433-7447.

34 X. Wang and Z. An, Macromol. Rapid Commun., 2019, 40, 1-14.

35 S. Sugihara, A. Blanazs, S. P. Armes, A. J. Ryan and A. L. Lewis, J. Am. Chem. Soc., 2011, 133, 15707-15713.

36 S. Perrier and P. Takolpuckdee, J. Polym. Sci., Part A: Polym. Chem., 2005, 43, 5347-5393.

37 G. Moad, E. Rizzardo and S. H. Thang, Aust. J. Chem., 2006, 59, 669-692.

38 J. Tan, H. Sun, M. Yu, B. S. Sumerlin and L. Zhang, ACS Macro Lett., 2015, 4, 1249-1253.

39 Y. Jiang, N. Xu, J. Han, Q. Yu, L. Guo, P. Gao, X. Lu and Y. Cai, Polym. Chem., 2015, 6, 4955-4965.

40 D. Zhou, S. Dong, R. P. Kuchel, S. Perrier and P. B. Zetterlund, Polym. Chem., 2017, 8, 3082-3089.

41 S. Y. Khor, J. F. Quinn, M. R. Whittaker, N. P. Truong and T. P. Davis, Macromol. Rapid Commun., 2019, 40, 1-22.

42 B. Karagoz, L. Esser, H. T. Duong, J. S. Basuki, C. Boyer and T. P. Davis, Polym. Chem., 2014, 5, 350-355.

43 W. Zhou, Q. Qu, Y. Xu and Z. An, ACS Macro Lett., 2015, 4, 495-499.

44 X. Zhang, S. Boissé, W. Zhang, P. Beaunier, F. D'Agosto, J. Rieger and B. Charleux, Macromolecules, 2011, 44, 41494158.

45 J. Rieger, C. Grazon, B. Charleux, D. Alaimo and C. Jérôme, J. Polym. Sci., Part A: Polym. Chem., 2009, 47, 2373-2390.

46 X. Wang, J. Zhou, X. Lv, B. Zhang and Z. An, Macromolecules, 2017, 50, 7222-7232.

47 A. B. Lowe and C. L. McCormick, Prog. Polym. Sci., 2007, 32, 283-351.
48 L. A. Fielding, J. A. Lane, M. J. Derry, O. O. Mykhaylyk and S. P. Armes, J. Am. Chem. Soc., 2014, 136, 5790-5798.

49 Y. Ma, P. Gao, Y. Ding, L. Huang, L. Wang, X. Lu and Y. Cai, Macromolecules, 2019, 52, 1033-1041.

50 C. A. Figg, A. Simula, K. A. Gebre, B. S. Tucker, D. M. Haddleton and B. S. Sumerlin, Chem. Sci., 2015, 6, 1230-1236.

51 J. N. Israelachvil, D. J. Mitchell and B. W. Ninham, J. Chem. Soc., Faraday Trans., 1975, 72, 1525-1568.

52 M. Antonietti and S. Förster, Adv. Mater., 2003, 15, 13231333.

53 A. Blanazs, S. P. Armes and A. J. Ryan, Macromol. Rapid Commun., 2009, 30, 267-277.

54 J. C. Foster, S. Varlas, B. Couturaud, J. R. Jones, R. Keogh, R. T. Mathers and R. K. O'Reilly, Angew. Chem., Int. Ed., 2018, 57, 15733-15737.

55 S. J. Byard, M. Williams, B. E. Mckenzie, A. Blanazs and S. P. Armes, Macromolecules, 2017, 50, 1482-1493.

56 J. R. Lovett, M. J. Derry, P. Yang, F. L. Hatton, N. J. Warren, P. W. Fowler and S. P. Armes, Chem. Sci., 2018, 9, 7138-7144.

57 O. O. Mykhaylyk, N. J. Warren, A. J. Parnell, G. Pfeifer and J. Laeuger, J. Polym. Sci., Part B: Polym. Phys., 2016, 54, 2151-2170.

58 O. O. Mykhaylyk, A. J. Parnell, A. Pryke and J. P. A. Fairclough, Macromolecules, 2012, 45, 5260-5272.

59 O. Glatter and O. Kratky, Small Angle X-ray Scattering, Academic Press, London, 1982, vol. 130.

60 G. Battaglia and A. J. Ryan, J. Am. Chem. Soc., 2005, 127, 8757-8764.

61 A. M. Rumyantsev, F. A. M. Leermakers, E. B. Zhulina, I. I. Potemkin and O. V. Borisov, Langmuir, 2019, 35, 26802691.

62 J. R. Lovett, N. J. Warren, L. P. D. Ratcliffe, M. K. Kocik and S. P. Armes, Angew. Chem., Int. Ed., 2015, 54, 1279-1283.

63 L. P. D. Ratcliffe, M. J. Derry, A. Ianiro, R. Tuinier and S. P. Armes, Angew. Chem., Int. Ed., 2019, 58, DOI: 10.1002/ anie.201909124. 